\title{
MUCOADHESIVE VAGINAL TABLETS OF NATAMYCIN FOR VAGINAL CANDIDIASIS
}

\author{
G. A. El-Gindy ${ }^{1 *}$, A. M. El-Sayed ${ }^{1}$, A. A. Mohamed ${ }^{1}$, S. A. Mohamed ${ }^{2}$ and Gh. M. Abdel-Aal ${ }^{1}$ \\ ${ }^{1}$ Department of Pharmaceutics, Faculty of Pharmacy, Assiut University, Assiut 71526, Egypt \\ ${ }^{2}$ Department of Obstetrics and Gynecology, Faculty of Medicine, Assiut University, Assiut, \\ 71526, Egypt
}

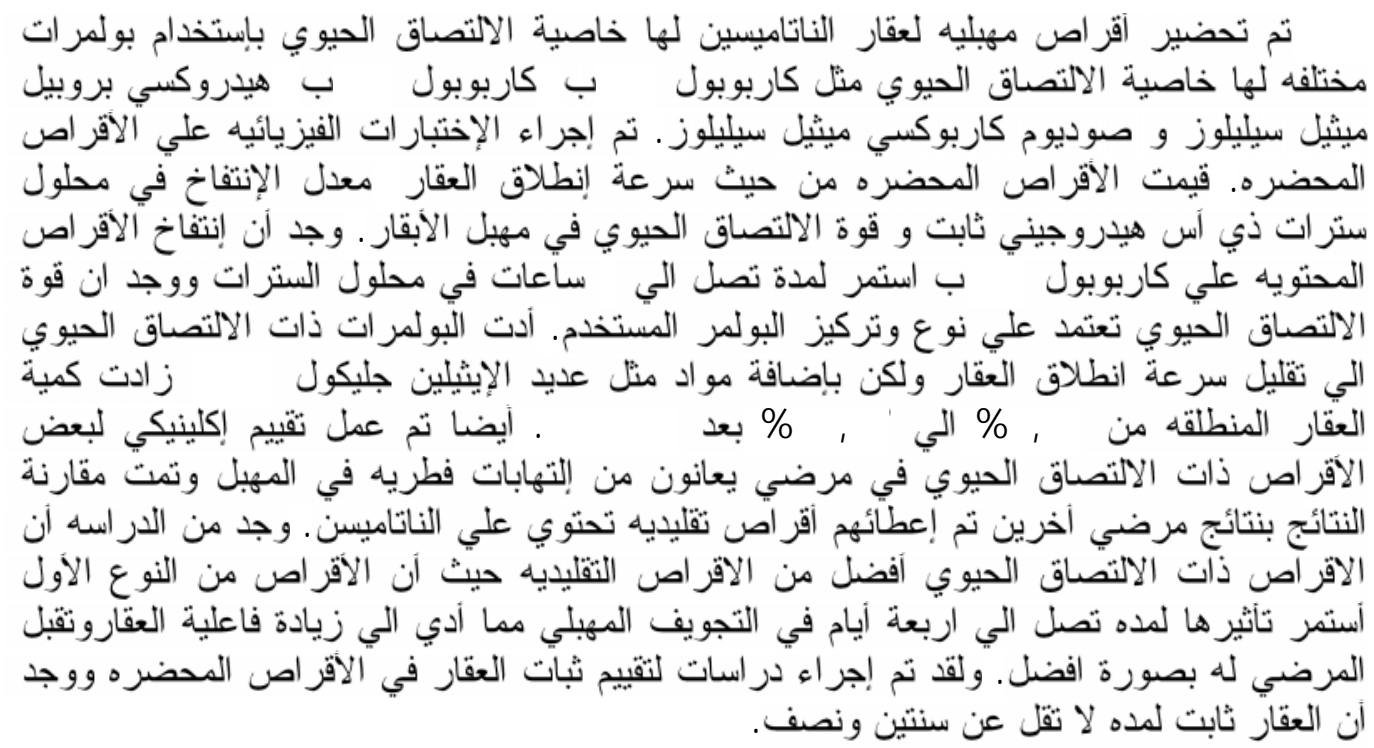

\begin{abstract}
Bioadhesive vaginal tablets of natamycin were formulated with different bioadhesive polymers such as carbopol 971p, carbopol 974p, hydroxypropyl methylcellulose, and sodium carboxymethylcellulose. Physical tests were applied to the tablets. The bioadhesive tablets were evaluated for drug release rate and swelling behaviour in citrate buffer solution and bioadhesive strength to mucosal tissue of cow vagina. The swelling of the tablets containing carbopol $974 \mathrm{p}$ was found to last for up to $6 \mathrm{hr}$ in citrate buffer solution. The force necessary to detach the tablets from the vaginal tissue was found to be dependent on the concentration and type of the bioadhesive polymer. The bioadhesive polymers were found to decrease the drug release rate. However, inclusion of polyethylene glycol 6000 in the formulations increased the released amount of the drug from $6.35 \%$ to $38.83 \%$ after $12 \mathrm{~h}$. The bioadhesive tablets were clinically evaluated in volunteers suffering from vaginal candidiasis and compared with conventional natamycin vaginal tablets. It was found that the bioadhesive tablets were more effective than the conventional tablets as they lasted about 4 days in the vaginal cavity and this could sustain the drug release and lead to better patient compliance. Accelerated stability studies were carried out and showed that the selected formulations were stable for not less than 2.5 years.
\end{abstract}

\section{INTRODUCTION}

A common microbial problem of the vulvovaginal tract is the acute and chronic infections with Candida albicans. ${ }^{1,2}$

Present commonly used conventional delivery systems, such as creams, foams, tablets, gels, irrigations, or pessaries suffer from many disadvantages such as their relatively short residence time. Moreover, multiple daily doses are often required, leading to systemic adverse effects and poor patient compliance. $^{3,4}$

The greatest advantages of bioadhesive tablets are the release of drug at a controlled 
rate and the possibility of maintaining them in the vagina for extended periods of time. They also enable lower dosing frequencies. ${ }^{5}$

Among the polymers, carbopol 974p, carbopol 971p and hydroxypropyl methylcellulose are ideal excipients in vaginal bioadhesive tablet formulations due to their high bioadhesive strengths. ${ }^{6-8}$

The main factors that govern the drug release rate over a predetermined time period from controlled release matrices are concentrations of the polymer and the drug in the tablet, drug solubility, diffusion coefficient and matrix porosity. ${ }^{9-14}$

This investigation describes the in-vitro development and aspects of the clinical assessment in humans of new bioadhesive tablets for the vaginal application of natamycin which is a polyene antifungal antibiotic active against Candida albicans and Trichomonas vaginalis. ${ }^{15}$

\section{MATERIALS AND METHODS}

\section{Materials}

Natamycin (NTM) was a gift sample from Yamanouchi Europe B.V., Netherlands; carbopol 971p (CP 971p) and 974p (CP 974p) from B.F. Goodrich Chemical Co., Cleveland, USA; hydroxypropyl methylcellulose (HPMC) and polyethylene glycol 4000 (PEG 4000) from Morgan Chemical Co., Egypt; sodium carboxymethylcellulose (NaCMC) from Arabic Laboratory Equipment Co., Egypt; avicel PH101 from Seppic, France; polyethylene glycol 6000 (PEG 6000) from Ubichem Ltd., Germany; anhydrous lactose from Elgomhouria Chem. Co., Egypt.

\section{Preparation of vaginal bioadhesive tablets}

Bioadhesive vaginal tablets were prepared by the direct compression method using the formula shown in Table 1. All ingredients of the tablets were mixed for 10 minutes by trituration in a glass mortar with pestle to obtain uniform mixing. The mixture $(200 \mathrm{mg})$ was then compressed using a $13 \mathrm{~mm}$ diameter die on a hydraulic press (Carver Inc., USA) using a compression force of 3 tones, and compression time of $30 \mathrm{sec}$. The tablets were 1.0-1.2 mm thick depending upon the polymer combination used.
Conventional vaginal tablets were also prepared by direct compression using a mixture of $12.5 \%$ natamycin, $43.75 \%$ avicel PH101 and $43.75 \%$ anhydrous lactose.

\section{Swelling studies}

Since the $\mathrm{pH}$ of the human vagina was found to be between 4 and $5,{ }^{16}$ tablet swelling was determined in citrate buffer $\mathrm{pH} 4.5$ (5.379 $\mathrm{g}$ citric acid and $6.47 \mathrm{~g}$ of sodium citrate made up to $1000 \mathrm{ml}$ with distilled water).

Three tablets from each formulation were placed in petri dish containing $50 \mathrm{ml}$ of the buffer maintained at $37 \pm 0.5^{\circ}$. The tablets were removed from the buffer after time intervals of $0.5,1,2,3,4,5$ and $6 \mathrm{hr}$. Excess water on the surface of the tablets was carefully absorbed using filter paper and their weight and volume changes were measured before and during the swelling. The diameter and thickness of the tablets were measured using a micrometer. Normalized swelling values were calculated either as the ratio of the volume in the swollen state to the dry state (normalized swelling volume) or as the ratio of the weight in the swollen state to the dry state (normalized swelling weight): $:^{14,17}$

\section{Drug release studies}

The drug release was determined using a dissolution apparatus which, according to USP method II (Paddle), consisted of six polycarbonate vessels placed in a water bath maintained at $37 \pm 0.5^{\circ}$ and stirred at a rate of 50 rpm. Each tablet was fixed at a glass slide by the aid of silicone adhesive to expose the upper surface only and hence the drug could be released only from this surface. The tablet was then immersed in the vessel containing $250 \mathrm{ml}$ of citrate buffer $\mathrm{pH}$ 4.5. Four tablets were examined at the same time. A drug-free tablet, used as blank, was introduced in the fifth vessel. With the aid of pipette, at regular intervals of time, an aliquot of dissolution medium were drawn and the content of natamycin was determined spectrophotometrically at $303 \mathrm{~nm}^{18}$ The amount of drug released was calculated on the basis of the standard calibration curve previously constructed. 
Table 1: Composition of natamycin bioadhesive vaginal tablets ( $\mathrm{mg} /$ tablet).

\begin{tabular}{|c|c|c|c|c|c|c|c|c|}
\hline Code & NTM & $\begin{array}{c}\mathrm{CP} \\
974 p \\
\end{array}$ & $\begin{array}{c}\mathrm{CP} \\
971 \mathrm{p} \\
\end{array}$ & $\begin{array}{l}\text { PEG } \\
4000 \\
\end{array}$ & $\begin{array}{l}\text { PEG } \\
6000 \\
\end{array}$ & HPMC & $\mathrm{NaCMC}$ & lactose \\
\hline $\mathrm{A} 1$ & 25 & 10 & - & - & - & 165 & - & - \\
\hline A2 & 25 & 10 & - & - & 10 & 155 & - & - \\
\hline A3 & 25 & 10 & - & - & 20 & 145 & - & - \\
\hline A4 & 25 & 10 & - & - & 40 & 125 & - & - \\
\hline A5 & 25 & 10 & - & - & 60 & 105 & - & - \\
\hline A6 & 25 & 10 & - & - & 80 & 85 & - & - \\
\hline A7 & 25 & 10 & - & - & 100 & 65 & - & - \\
\hline $\mathrm{B} 1$ & 25 & 20 & - & - & - & 155 & - & - \\
\hline B2 & 25 & 20 & - & - & 10 & 145 & - & - \\
\hline B3 & 25 & 20 & - & - & 20 & 135 & - & - \\
\hline $\mathrm{B} 4$ & 25 & 20 & - & - & 40 & 115 & - & - \\
\hline B5 & 25 & 20 & - & - & 60 & 95 & - & - \\
\hline B6 & 25 & 20 & - & - & 80 & 75 & - & - \\
\hline B7 & 25 & 20 & - & - & 100 & 55 & - & - \\
\hline $\mathrm{C} 1$ & 25 & 30 & - & - & - & 145 & - & - \\
\hline $\mathrm{C} 2$ & 25 & 30 & - & - & 10 & 135 & - & - \\
\hline $\mathrm{C} 3$ & 25 & 30 & - & - & 20 & 125 & - & - \\
\hline $\mathrm{C} 4$ & 25 & 30 & - & - & 40 & 105 & - & - \\
\hline $\mathrm{C} 5$ & 25 & 30 & - & - & 60 & 85 & - & - \\
\hline C6 & 25 & 30 & - & - & 80 & 65 & - & - \\
\hline $\mathrm{C} 7$ & 25 & 30 & - & - & 100 & 45 & - & - \\
\hline D1 & 25 & 40 & - & - & - & 135 & - & - \\
\hline D2 & 25 & 40 & - & - & 10 & 125 & - & - \\
\hline D3 & 25 & 40 & - & - & 20 & 115 & - & - \\
\hline D4 & 25 & 40 & - & - & 40 & 95 & - & - \\
\hline D5 & 25 & 40 & - & - & 60 & 75 & - & - \\
\hline D6 & 25 & 40 & - & - & 80 & 55 & - & - \\
\hline D7 & 25 & 40 & - & - & 100 & 35 & - & - \\
\hline E1 & 25 & - & 5 & 40 & - & - & 80 & 50 \\
\hline E2 & 25 & - & 10 & 40 & - & - & 75 & 50 \\
\hline E3 & 25 & - & 15 & 40 & - & - & 70 & 50 \\
\hline E4 & 25 & - & 20 & 40 & - & - & 65 & 50 \\
\hline E5 & 25 & - & 25 & 40 & - & - & 60 & 50 \\
\hline E6 & 25 & - & 30 & 40 & - & - & 50 & 50 \\
\hline
\end{tabular}

NTM, natamycin; CP 974p, carbopol 974p; CP 971p, carbopol 971p; HPMC, hydroxypropyl methylcellulose; NaCMC, sodium carboxymethylcellulose; ; PEG 4000, polyethylene glycol 4000; PEG 6000, polyethylene glycol 6000. 


\section{In situ bioadhesion test}

The bioadhesive strengths of the tablets were measured according to previously published method ${ }^{17}$ depicted in Figure 1 using cow vagina as a model mucosal membrane. The vaginas of freshly sacrificed cows were removed and rapidly stored at $-30^{\circ}$ until ready for the bioadhesion studies. A circular piece (surface area $2 \mathrm{~cm}^{2}$ ) of the vagina was cut and brought to room temperature in saline solution, then glued with cyanoacrylate adhesive on the ground surface of a tissue holder made of Plexiglas. Similarly, the tablet was glued to another holder of the same size. Thereafter, the surface of the mucosal membrane was first blotted with a filter paper and then moistened with $25 \mu \mathrm{l}$ of citrate buffer $\mathrm{pH} 4.5$. The two holders with mucosal membrane and tablet were brought into contact with each other with uniform and constant stress of $4.5 \mathrm{KPa}$ for 5 min (preload time) to facilitate adhesion bonding. The tissue holder with vagina was allowed to hang on an iron stand with the help of a piece of aluminum wire. A prewieghed lightweight polypropylene bag was attached to the hook on the backside of the formulation holder with a piece of aluminum wire. After a preload time of $5 \mathrm{~min}$, water was added to the polypropylene bag through an intravenous infusion set at a constant rate of one drop/sec until the tablet detached form the tissue. The water collected in the bag was measured and expressed as weight (g) required for detachment. Each experiment was repeated three times.

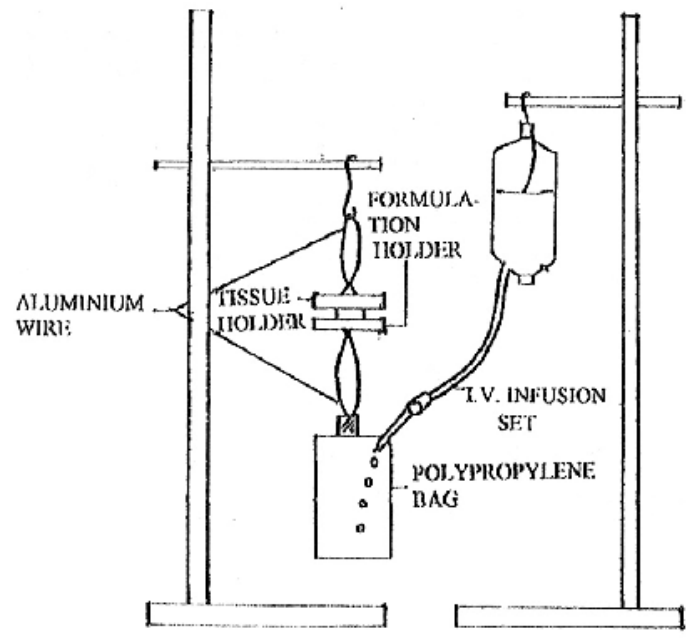

Fig. 1: Modified apparatus for in-vitro bioadhesion test.

\section{Clinical evaluation of selected bioadhesive vaginal tablets}

29 patients (aged 18-45 years) attended the outpatient clinic of Obstetric and Gynecology Department, Assiut University hospital suffering from vaginal candidiasis were included in this study. Two satisfactory bioadhesive vaginal tablet formulations (D6 and E6) in terms of bioadhesive strengths and percent drug release were selected. In this study, the bioadhesive tablets were prepared using triple amounts of drug and bioadhesive polymers where each bioadhesive tablet contains $75 \mathrm{mg}$ of natamycin while each conventional vaginal tablet contains $25 \mathrm{mg}$ of the drug.

In a double-blind study, the patients were randomly allocated to receive D6 or E6. Both groups were compared with a third group of patients given the conventional natamycin tablets. In the case of treatment with the bioadhesive tablets, a single tablet was applied to the cervix at the outpatient clinic. The bioadhesive tablets were inserted digitally in the posterior vaginal fornix's through examination after they had complete medical and obstetrical evaluation. The trial had the approval of Committee of Medical ethics, Faculty of Medicine, Assiut University. Patients were asked to record the time of the loss of a tablet. Each patient taking the conventional natamycin vaginal tablets was given three tablets, one tablet was applied in the same area as the bioadhesive tablet and the patient was instructed to apply the two remaining tablets on the two consecutive days. A vaginal swab was taken from each patient before the application of the tablets and one week after the application. Aliquots from the swabs were inoculated into sabouraud agar plates, which were incubated at $37^{\circ}$ for $24 \mathrm{hr}$. Then the colonies of Candida albicans were counted. The patient's complaints, the results of the clinical investigations and the results of the bacteriological evaluation were recorded on an evaluation sheet for each patient. The clinical and bacteriological evaluations were performed before treatment and one week after treatment. The diagnosis of vaginal candidiasis was based on the following criteria: positive growth of candida colonies on sabouraud agar plates and presence of vaginal discharge and itching. The patients were considered cured if 
none of the above-mentioned diagnostic criteria was fulfilled.

\section{Stability testing}

Stability studies on the final formulations were carried out to determine the physical stability of the formulations under accelerated storage conditions of temperature and the effect of the presence of formulation additives on the stability of the drug.

The bioadhesive vaginal tablets were stored in closed amber glass bottles. These bottles were placed in hot air ovens maintained at 30,37 and $45^{\circ}$. General appearance, organoleptic properties and active drug contents of the tablets were determined after 0 , $15,30,45,60,75,90,120,150$ and 180 days.

For the determination of active drug content, a pharmacopeial method was used. ${ }^{19}$ The chromatographic system used was (HPLC, Knauer, Germany) which consists of a model HP 1100 series quaternary, isocratic elution pump and HP 1100 series variable wavelength UV-vis detector. Chromatographic separation was carried out using a Knauer C18 column $(150 \times 4 \mathrm{~mm}, 5 \mathrm{~m})$ and the detection was carried out at $303 \mathrm{~nm}$.

The mobile phase consisted of $3.0 \mathrm{~g}$ ammonium acetate, $1.0 \mathrm{~g}$ ammonium chloride, $760 \mathrm{ml}$ water, $5.0 \mathrm{ml}$ tetrahydrofuran and 140 $\mathrm{ml}$ acetonitrile. The flow rate was $2.0 \mathrm{ml} / \mathrm{min}$ and the injection volume was 201 .

\section{Statistical analysis}

Statistical analysis of the relevant data was done using Student's t-tests.

\section{RESULTS AND DISCUSSION}

\section{Swelling studies}

When the tablets were examined for their swelling behavior in citrate buffer $\mathrm{pH} 4.5$, as anticipated the amount and nature of the bioadhesive polymer had an important effect on their swelling characteristics.

Tables 2-5 show the normalized swelling volume and weight values of different bioadhesive vaginal tablet formulations. The tablets containing CP 974p and HPMC continued to swell for up to 6 hours in citrate buffer. However, formula A7 which contains 50\% PEG 6000 and 5\% CP 974p begins to diffuse and looses its shape after 4 hours so no measurements could be done after this time. This could be attributed to the high percentage of PEG 6000 and the low percentage of CP 974p, which facilitate the disintegration of the tablets. It was found that the normalized swelling weight and volume values increased with the increase in the amount of CP 974p.

Table 2: Normalized swelling volume (Q) and weight (q) of bioadhesive natamycin vaginal tablets containing 5\% CP 974p in citrate buffer $\mathrm{pH} 4.5$. Values are expressed as mean \pm S.D., $\mathrm{n}=3$. E: erosion.

\begin{tabular}{|c|c|c|c|c|c|c|c|c|c|c|c|c|c|c|}
\hline \multirow{2}{*}{$\begin{array}{c}\text { Time } \\
(\mathrm{hr})\end{array}$} & \multicolumn{2}{|c|}{ A1 } & \multicolumn{2}{|c|}{ A2 } & \multicolumn{2}{|c|}{ A3 } & \multicolumn{2}{|c|}{ A4 } & \multicolumn{2}{|c|}{ A5 } & \multicolumn{2}{|c|}{ A6 } & \multicolumn{2}{|c|}{ A7 } \\
\hline & $\mathrm{Q}$ & $\mathrm{Q}$ & $\mathrm{Q}$ & $q$ & $\mathrm{Q}$ & $\mathrm{q}$ & $\mathrm{Q}$ & $\mathrm{q}$ & $\mathrm{Q}$ & $q$ & $\mathrm{Q}$ & $q$ & $\mathrm{Q}$ & $q$ \\
\hline \multirow{2}{*}{0.5} & 1.27 & 1.59 & 2.20 & 1.78 & 2.21 & 1.75 & 2.52 & 1.75 & 2.80 & 1.74 & 2.48 & 1.65 & 2.34 & 1.57 \\
\hline & \pm .01 & \pm .12 & \pm .03 & \pm .07 & \pm .08 & \pm .13 & \pm .05 & \pm .21 & \pm .03 & \pm .25 & \pm .01 & \pm .08 & \pm .06 & \pm .05 \\
\hline \multirow{2}{*}{1.0} & 1.64 & 1.73 & 2.49 & 2.01 & 2.80 & 2.04 & 2.73 & 2.12 & 2.93 & 2.11 & 2.57 & 1.93 & 3.67 & 1.97 \\
\hline & \pm 0.1 & \pm .07 & \pm .07 & \pm .13 & \pm .05 & \pm .13 & \pm .09 & \pm .21 & \pm .06 & \pm .23 & \pm .02 & \pm .03 & \pm .07 & \pm .04 \\
\hline \multirow{2}{*}{2.0} & 2.23 & 2.09 & 3.06 & 2.51 & 3.61 & 2.47 & 3.96 & 2.4 & 4.11 & 2.45 & 3.79 & 2.41 & 4.47 & 2.41 \\
\hline & \pm .12 & \pm .11 & \pm .06 & \pm .29 & \pm .10 & \pm .23 & \pm .09 & \pm .19 & \pm .06 & \pm .35 & \pm .04 & \pm .20 & \pm .06 & \pm .1 \\
\hline \multirow{2}{*}{3.0} & 2.73 & 2.36 & 3.78 & 2.68 & 3.98 & 2.75 & 4.53 & 2.72 & 4.41 & 2.66 & 4.36 & 2.55 & 5.48 & 2.66 \\
\hline & \pm .02 & \pm .04 & \pm .03 & \pm .14 & \pm .11 & \pm .17 & \pm .15 & \pm .19 & \pm .04 & \pm .31 & \pm .02 & \pm .1 & \pm .16 & \pm .05 \\
\hline \multirow{2}{*}{4.0} & 2.90 & 2.45 & 4.49 & 2.96 & 4.48 & 2.98 & 5.05 & 2.94 & 4.98 & 2.92 & 5.21 & 2.8 & 6.33 & 3.05 \\
\hline & \pm .08 & \pm 017 & \pm .01 & \pm .27 & \pm .16 & \pm .08 & \pm .11 & \pm .24 & \pm .05 & \pm .15 & \pm .03 & \pm .06 & \pm .13 & \pm .12 \\
\hline \multirow{2}{*}{5.0} & 3.33 & 2.61 & 5.14 & 3.1 & 5.33 & 3.21 & 5.68 & 3.15 & 5.68 & 3.05 & 5.96 & 3 & & \\
\hline & \pm .13 & \pm .1 & \pm .21 & \pm .21 & \pm .22 & \pm .25 & \pm .15 & \pm .38 & \pm .07 & \pm .31 & \pm .04 & \pm .26 & $\mathrm{E}$ & $\mathrm{L}$ \\
\hline \multirow{2}{*}{6.0} & 3.90 & 2.72 & 5.53 & 3.18 & 5.63 & 3.35 & 6.81 & 3.29 & 7.10 & 3.36 & 7.00 & 3.15 & & \\
\hline & \pm .13 & \pm .04 & \pm .04 & \pm .03 & \pm .18 & \pm .18 & \pm .11 & \pm .45 & \pm .07 & \pm .29 & \pm .14 & \pm .34 & & \\
\hline
\end{tabular}


Table 3: Normalized swelling volume $(\mathrm{Q})$ and weight $(\mathrm{q})$ of bioadhesive natamycin vaginal tablets containing $10 \% \mathrm{CP} 974 \mathrm{p}$ in citrate buffer $\mathrm{pH}$ 4.5. Values are expressed as mean \pm S.D., $\mathrm{n}=3$.

\begin{tabular}{|c|c|c|c|c|c|c|c|c|c|c|c|c|c|c||}
\hline \multirow{2}{*}{$\begin{array}{c}\text { Time } \\
(\mathrm{hr})\end{array}$} & \multicolumn{2}{|c|}{$\mathrm{B} 1$} & \multicolumn{2}{|c|}{$\mathrm{B} 2$} & \multicolumn{2}{|c|}{$\mathrm{B} 3$} & \multicolumn{2}{|c|}{$\mathrm{B} 4$} & \multicolumn{2}{c|}{ B5 } & \multicolumn{3}{|c|}{ B6 } & \multicolumn{3}{|c|}{ B7 } \\
\cline { 2 - 16 } & $\mathrm{Q}$ & $\mathrm{q}$ & $\mathrm{Q}$ & $\mathrm{q}$ & $\mathrm{Q}$ & $\mathrm{q}$ & $\mathrm{Q}$ & $\mathrm{q}$ & $\mathrm{Q}$ & $\mathrm{q}$ & $\mathrm{Q}$ & $\mathrm{q}$ & $\mathrm{Q}$ & $\mathrm{q}$ \\
\hline \multirow{2}{*}{0.5} & 1.67 & 1.61 & 2.52 & 1.8 & 2.30 & 1.8 & 2.65 & 1.93 & 2.71 & 1.75 & 2.49 & 1.87 & 2.41 & 2.1 \\
& \pm .06 & \pm .2 & \pm .13 & \pm .04 & \pm .01 & \pm .07 & \pm .07 & \pm .22 & \pm .13 & \pm .06 & \pm .03 & \pm .09 & \pm .05 & \pm .16 \\
\hline \multirow{2}{*}{1.0} & 2.13 & 1.97 & 2.87 & 2.21 & 3.13 & 2.1 & 2.88 & 2.23 & 2.90 & 2.23 & 2.60 & 2.26 & 3.92 & 2.39 \\
& \pm .06 & \pm .05 & \pm .13 & \pm .11 & \pm .07 & \pm .14 & \pm .07 & \pm .02 & \pm .14 & \pm .05 & \pm .01 & \pm .03 & \pm .03 & \pm .04 \\
\hline \multirow{2}{*}{2.0} & 2.58 & 2.22 & 3.91 & 2.72 & 3.79 & 2.9 & 4.04 & 2.85 & 4.16 & 2.87 & 3.94 & 2.92 & 5.03 & 2.93 \\
& \pm .02 & \pm .16 & \pm .14 & \pm .03 & \pm .33 & \pm .03 & \pm .25 & \pm .005 & \pm .11 & \pm .16 & \pm .06 & \pm .11 & \pm .16 & \pm .13 \\
\hline \multirow{2}{*}{3.0} & 2.95 & 2.38 & 4.39 & 3.12 & 4.54 & 3.11 & 4.41 & 3.36 & 4.53 & 3.48 & 4.52 & 3.45 & 6.26 & 3.21 \\
& \pm .06 & \pm .19 & \pm .09 & \pm .27 & \pm .16 & \pm .3 & \pm .17 & \pm .05 & \pm .22 & \pm .03 & \pm .06 & \pm .05 & \pm .06 & \pm .13 \\
\hline \multirow{2}{*}{4.0} & 3.23 & 2.58 & 5.11 & 3.76 & 4.88 & 3.36 & 5.39 & 3.72 & 5.33 & 3.68 & 5.35 & 3.69 & 6.82 & 3.5 \\
& \pm .06 & \pm .02 & \pm .25 & \pm .09 & \pm .17 & \pm .37 & \pm .3 & \pm .19 & \pm .21 & \pm .22 & \pm .02 & \pm .06 & \pm .09 & \pm .27 \\
\hline \multirow{2}{*}{5.0} & 4.10 & 2.98 & 6.08 & 3.88 & 5.69 & 3.67 & 6.24 & 4.05 & 5.94 & 3.95 & 6.09 & 3.78 & 8.60 & 3.63 \\
& \pm .15 & \pm .17 & \pm .22 & \pm .15 & \pm .25 & \pm .3 & \pm .3 & \pm .1 & \pm .16 & \pm .12 & \pm .1 & \pm .13 & \pm .02 & \pm .07 \\
\hline \multirow{2}{*}{6.0} & 4.79 & 3.14 & 6.86 & 4.09 & 6.06 & 3.92 & 7.54 & 4.5 & 7.11 & 4.23 & 7.34 & 3.91 & 11.13 & 3.81 \\
& \pm .14 & \pm .07 & \pm .25 & \pm .27 & \pm .19 & \pm .32 & \pm .24 & \pm .13 & \pm .59 & \pm .14 & \pm .08 & \pm .08 & \pm .31 & \pm .07 \\
\hline
\end{tabular}

Table 4: Normalized swelling volume (Q) and weight (q) of bioadhesive natamycin vaginal tablets containing $15 \% \mathrm{CP} 974 \mathrm{p}$ in citrate buffer $\mathrm{pH} 4.5$. Values are expressed as mean \pm S.D., $\mathrm{n}=3$.

\begin{tabular}{|c|c|c|c|c|c|c|c|c|c|c|c|c|c|c||}
\hline \multirow{2}{*}{$\begin{array}{c}\text { Time } \\
\text { (hr) }\end{array}$} & \multicolumn{2}{|c|}{ C1 } & \multicolumn{2}{c|}{ C2 } & \multicolumn{2}{c|}{ C3 } & \multicolumn{2}{c|}{ C4 } & \multicolumn{2}{c|}{ C5 } & \multicolumn{2}{|c|}{ C6 } & \multicolumn{2}{|c|}{ C7 } \\
\hline \multirow{2}{*}{0.5} & 2.07 & $\mathrm{q}$ & $\mathrm{Q}$ & $\mathrm{q}$ & $\mathrm{Q}$ & $\mathrm{q}$ & $\mathrm{Q}$ & $\mathrm{q}$ & $\mathrm{Q}$ & $\mathrm{q}$ & $\mathrm{Q}$ & $\mathrm{q}$ & $\mathrm{Q}$ & $\mathrm{q}$ \\
& \pm .08 & \pm .03 & 2.79 & \pm .9 & 2.48 & 1.9 & 2.62 & 2.02 & 2.61 & 2.06 & 2.39 & 2.26 & 2.84 & 2.14 \\
& 2.37 & 2.03 & 3.01 & 2.13 & \pm .15 & \pm .13 & \pm .06 & \pm .04 & \pm .13 & \pm .07 & \pm .04 & \pm .14 & \pm .04 & .006 \\
\hline \multirow{2}{*}{1.0} & \pm .04 & \pm .16 & \pm .09 & \pm .15 & \pm .07 & \pm .14 & 2.9 & 2.27 & 2.82 & 2.38 & 2.76 & 2.43 & 4.40 & 2.47 \\
& 2.79 & 20.55 & 4.06 & 2.92 & 3.56 & 3.04 & \pm .1 & \pm .01 & \pm .09 & \pm .04 & \pm .07 & \pm .08 & \pm .12 & \pm .05 \\
\hline \multirow{2}{*}{2.0} & \pm .15 & \pm .07 & \pm .09 & \pm .23 & \pm .01 & \pm .01 & \pm .17 & \pm .006 & 3.41 & 3 & 4.32 & 3.01 & 5.41 & 3.06 \\
& 3.22 & 2.97 & 4.77 & 3.62 & 4.90 & 3.47 & 4.68 & 3.55 & 4.89 & 3.02 & \pm .06 & \pm .15 & \pm .07 & \pm .04 \\
\hline \multirow{2}{*}{3.0} & \pm .16 & \pm .19 & \pm .01 & \pm .04 & \pm .13 & \pm .05 & \pm .1 & \pm .07 & \pm .17 & \pm .06 & \pm .09 & \pm .64 & 6.38 & 3.4 \\
& \pm .09 & \pm .06 & \pm .05 \\
\hline \multirow{2}{*}{4.0} & 3.67 & 3.35 & 5.51 & 3.92 & 5.13 & 3.89 & 6.04 & 4.05 & 5.61 & 4.03 & 6.03 & 3.85 & 7.19 & 3.62 \\
& \pm .17 & \pm .1 & \pm .19 & \pm .03 & \pm .13 & \pm .004 & \pm .16 & \pm .006 & \pm .22 & \pm .01 & \pm .16 & \pm .04 & \pm .10 & \pm .14 \\
\hline \multirow{2}{*}{5.0} & 4.70 & 3.65 & 6.57 & 4.17 & 6.33 & 4.23 & 6.92 & 4.37 & 6.14 & 4.25 & 7.20 & 3.95 & 8.99 & 3.76 \\
& \pm .26 & \pm .08 & \pm .1 & \pm .02 & \pm .02 & \pm .06 & \pm .24 & \pm .24 & \pm .24 & \pm .04 & \pm .07 & \pm .04 & \pm .36 & \pm .01 \\
\hline \multirow{2}{*}{6.0} & 5.60 & 4.02 & 7.23 & 4.55 & 6.72 & 4.68 & 7.40 & 4.59 & 7.54 & 4.53 & 8.05 & 4.2 & 10.63 & 3.95 \\
& \pm .29 & \pm .11 & \pm .15 & \pm .15 & \pm .25 & \pm .06 & \pm .2 & \pm .21 & \pm .46 & \pm .06 & \pm .03 & \pm .13 & \pm .22 & \pm .11 \\
\hline \hline
\end{tabular}


Table 5: Normalized swelling volume (Q) and weight (q) of bioadhesive natamycin vaginal tablets containing 20\% CP 974p in citrate buffer $\mathrm{pH}$ 4.5. Values are expressed as mean \pm S.D., $\mathrm{n}=3$.

\begin{tabular}{|c|c|c|c|c|c|c|c|c|c|c|c|c|c|c|}
\hline \multirow{2}{*}{$\begin{array}{c}\text { Time } \\
\text { (hr) }\end{array}$} & \multicolumn{2}{|c|}{ D1 } & \multicolumn{2}{|c|}{ D2 } & \multicolumn{2}{|c|}{ D3 } & \multicolumn{2}{|c|}{ D4 } & \multicolumn{2}{|c|}{ D5 } & \multicolumn{2}{|c|}{ D6 } & \multicolumn{2}{|c|}{ D7 } \\
\hline & Q & $q$ & $\mathrm{Q}$ & $q$ & $\mathrm{Q}$ & $q$ & $\mathrm{Q}$ & $q$ & $\mathrm{Q}$ & $q$ & Q & $q$ & $\mathrm{Q}$ & $q$ \\
\hline \multirow{2}{*}{0.5} & 2.33 & 1.84 & 2.80 & 1.92 & 2.46 & 1.92 & 2.62 & 2.11 & 3.07 & 2.13 & 2.57 & 2.43 & 3.09 & 2.19 \\
\hline & \pm .04 & \pm .06 & \pm .11 & \pm .13 & \pm .07 & \pm .13 & \pm .02 & \pm .003 & \pm .16 & \pm .01 & \pm .08 & \pm .04 & \pm .05 & \pm .02 \\
\hline \multirow{2}{*}{1.0} & 2.62 & 2.09 & 3.46 & 2.52 & 3.84 & 2.52 & 2.91 & 2.42 & 3.70 & 2.45 & 3.06 & 2.61 & 4.43 & 2.52 \\
\hline & \pm .06 & \pm .12 & \pm .03 & \pm .002 & \pm .13 & $\begin{array}{r} \pm .002 \\
\end{array}$ & \pm .04 & 0.02 & \pm .12 & \pm .08 & \pm .11 & \pm .19 & \pm .08 & \pm .06 \\
\hline \multirow{2}{*}{2.0} & 3.43 & 2.7 & 4.24 & 3.14 & 4.29 & 3.14 & 4.31 & 3.02 & 4.69 & 3.12 & 4.97 & 3.1 & 5.71 & 3.17 \\
\hline & \pm .16 & \pm .14 & \pm .15 & \pm .12 & \pm .09 & \pm .12 & \pm .07 & \pm .05 & \pm .21 & \pm .02 & \pm .10 & \pm .11 & \pm .10 & \pm .03 \\
\hline \multirow{2}{*}{3.0} & 3.69 & 3.48 & 5.27 & 3.69 & 5.42 & 3.69 & 4.66 & 3.69 & 5.20 & 3.78 & 5.47 & 3.74 & 6.78 & 3.74 \\
\hline & \pm .13 & \pm .07 & \pm .14 & \pm .17 & \pm .15 & \pm .17 & \pm .04 & \pm .004 & \pm .23 & \pm .009 & \pm .15 & \pm .02 & \pm .13 & \pm .12 \\
\hline \multirow{2}{*}{4.0} & 4.46 & 3.6 & 5.89 & 3.93 & 6.24 & 3.93 & 6.01 & 4.32 & 5.85 & 4.12 & 6.27 & 3.95 & 8.76 & 3.88 \\
\hline & \pm .35 & \pm .15 & \pm .31 & \pm .03 & \pm .18 & \pm .03 & \pm .04 & \pm .12 & \pm .29 & \pm .05 & \pm .14 & \pm .07 & \pm .29 & \pm .13 \\
\hline \multirow{2}{*}{5.0} & 5.73 & 3.95 & 6.52 & 4.34 & 6.90 & 4.34 & 6.91 & 4.42 & 6.66 & 4.33 & 8.07 & 4.4 & 10.86 & 3.92 \\
\hline & \pm .33 & \pm .21 & \pm .09 & \pm .006 & \pm .12 & \pm .006 & \pm .07 & \pm .16 & \pm .32 & \pm .08 & \pm .19 & \pm .007 & \pm .20 & \pm .1 \\
\hline \multirow{2}{*}{6.0} & 6.75 & 4.24 & 7.63 & 4.59 & 7.54 & 4.59 & 7.80 & 4.73 & 8.37 & 4.62 & 8.87 & 4.94 & 11.24 & 4.43 \\
\hline & \pm .33 & \pm .09 & \pm .19 & \pm .05 & \pm .15 & \pm .05 & \pm .15 & \pm .02 & \pm .33 & \pm .11 & \pm .15 & \pm .1 & \pm .07 & \pm .09 \\
\hline
\end{tabular}

Maximum normalized swelling volume and weight values were obtained with the formulations containing 20\% CP 974p. The swelling of the tablets containing $\mathrm{NaCMC}$, lactose and PEG 4000 was rapid and the tablets lost their shape and diffused in the citrate medium after the first $45 \mathrm{~min}$ and therefore their normalized swelling values could not be determined.

\section{In situ bioadhesion studies}

According to the detachment tests (Table 6), the forces necessary to detach the tablets from the vaginal tissue depended upon the concentration of CP 974p and CP 971p. In A to $D$ and $E_{1}$ to $E_{6}$ tablet formulations that contain CP 974p and CP 971p respectively, the necessary forces decreased as the CP $974 p$ or CP 971p amount decreased (Table 6). These results are in agreement with earlier studies ${ }^{20-22}$ for bioadhesive performance of different polymers. The increase in PEG 6000 contents in the formulations has resulted in decreasing the bioadhesive strengths of the tablets. This was anticipated because the increase in PEG contents was associated by an equal decrease in the contents of HPMC, which is more adhesive than PEG. ${ }^{6}$
Table 6: Detachment forces between bioadhesive tablets and cow vaginal mucus.

\begin{tabular}{|c|c|c|c|}
\hline Formula & $\begin{array}{c}\text { Bioadehsive } \\
\text { force }(\mathrm{g})^{\mathrm{a}}\end{array}$ & Formula & $\begin{array}{c}\text { Bioadehsive } \\
\text { force }(\mathrm{g})^{\mathrm{a}}\end{array}$ \\
\hline A1 & $29.23 \pm 1.91$ & C4 & $35.58 \pm 0.45$ \\
\hline A2 & $25.74 \pm 0.61$ & C5 & $28.78 \pm 2.08$ \\
\hline A3 & $20.4 \pm 0.74$ & C6 & $25.88 \pm 0.62$ \\
\hline A4 & $17.02 \pm 0.27$ & C7 & $22.62 \pm 0.46$ \\
\hline A5 & $15.63 \pm 0.61$ & D1 & $81.37 \pm 0.96$ \\
\hline A6 & $13.38 \pm 0.63$ & D2 & $67.61 \pm 1.55$ \\
\hline A7 & $10.71 \pm 0.69$ & D3 & $60.34 \pm 1.25$ \\
\hline B1 & $41.09 \pm 1.12$ & D4 & $50.51 \pm 1.62$ \\
\hline B2 & $34.09 \pm 0.15$ & D5 & $46.25 \pm 0.91$ \\
\hline B3 & $26.13 \pm 0.97$ & D6 & $41.23 \pm 0.97$ \\
\hline B4 & $21.71 \pm 0.62$ & D7 & $34.94 \pm 1.84$ \\
\hline B5 & $19.14 \pm 0.95$ & E1 & $7.39 \pm 0.64$ \\
\hline B6 & $17.94 \pm 0.2$ & E2 & $13.44 \pm 1.16$ \\
\hline B7 & $16.26 \pm 0.92$ & E3 & $18.91 \pm 1.89$ \\
\hline C1 & $55.47 \pm 0.7$ & E4 & $26.83 \pm 0.7$ \\
\hline C2 & $48.41 \pm 0.61$ & E5 & $33.28 \pm 1.01$ \\
\hline C3 & $42.33 \pm 0.64$ & E6 & $40.55 \pm 0.52$ \\
\hline \hline
\end{tabular}

${ }^{\mathrm{a}}$ Mean \pm S.D., $\mathrm{n}=3$

\section{In-vitro drug release studies}

The in-vitro drug release profiles of natamycin from different bioadhesive vaginal 
tablets are shown in Figs. 2-6. It was apparent from the plots that an increase in the bioadhesive polymer contents (CP 974p in formulations A-D and CP 971p in formulations E1-E6) was associated with a corresponding decrease in the drug release rate. This could be attributed to the extensive swelling of the polymers at high concentrations. This extensive swelling created a thick gel barrier for drug diffusion. These observations were in good agreement with those obtained by other workers. ${ }^{22}$

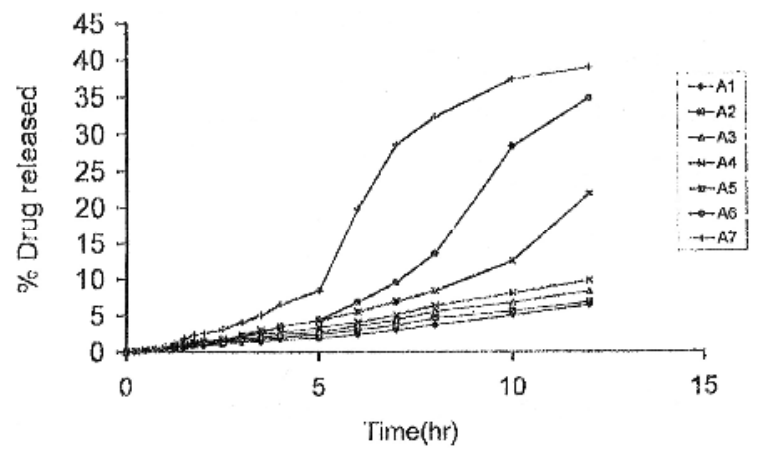

Fig. 2: In-vitro release profiles of natamycin from bioadhesive vaginal tablet formulations containing $5 \% \quad \mathrm{CP} \quad 974 \mathrm{p}$ and different concentrations of PEG 6000.

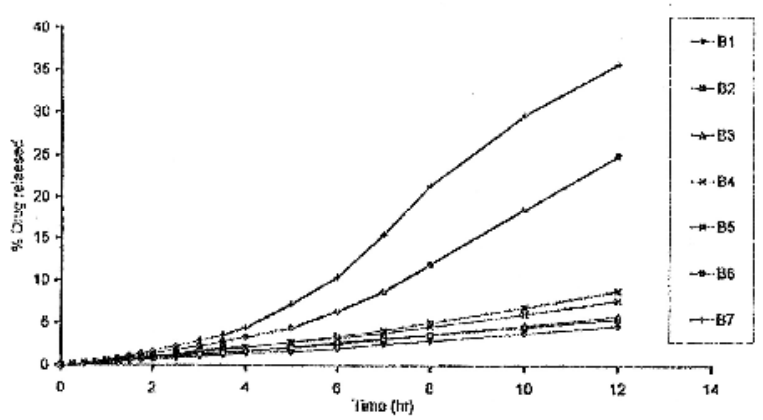

Fig. 3: In-vitro release profiles of natamycin from bioadhesive vaginal tablet formulations containing $10 \% \quad \mathrm{CP} \quad 974 \mathrm{p}$ and different concentrations of PEG 6000.

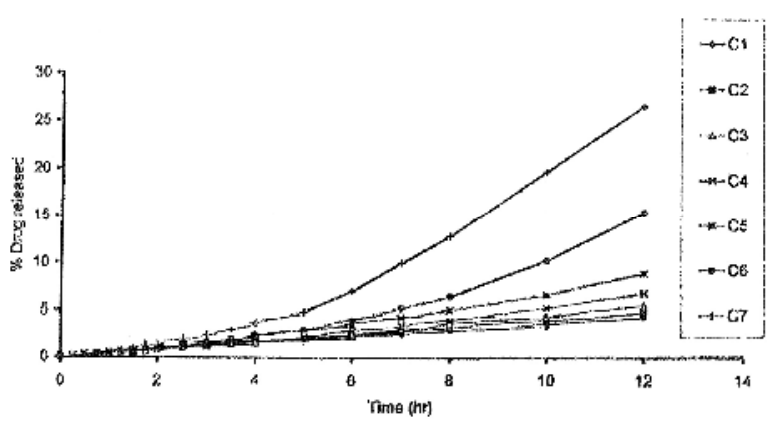

Fig. 4: In-vitro release profiles of natamycin from bioadhesive vaginal tablet formulations containing $15 \% \quad \mathrm{CP} \quad 974 \mathrm{p}$ and different concentrations of PEG 6000.

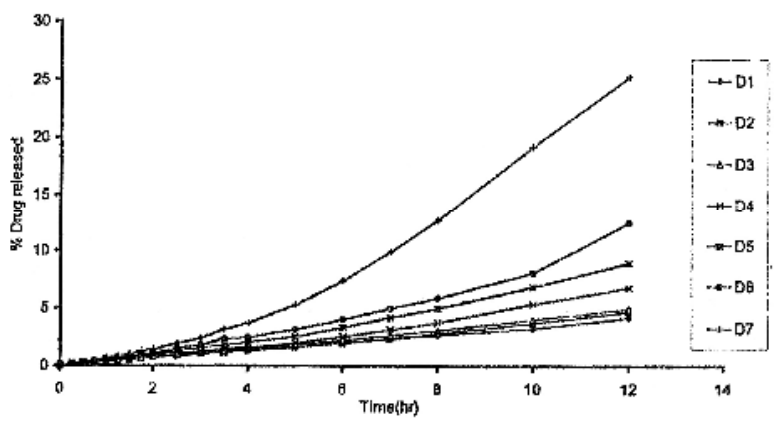

Fig. 5: In-vitro release profiles of natamycin from bioadhesive vaginal tablet formulations containing $20 \% \quad \mathrm{CP} \quad 974 \mathrm{p}$ and different concentrations of PEG 6000.

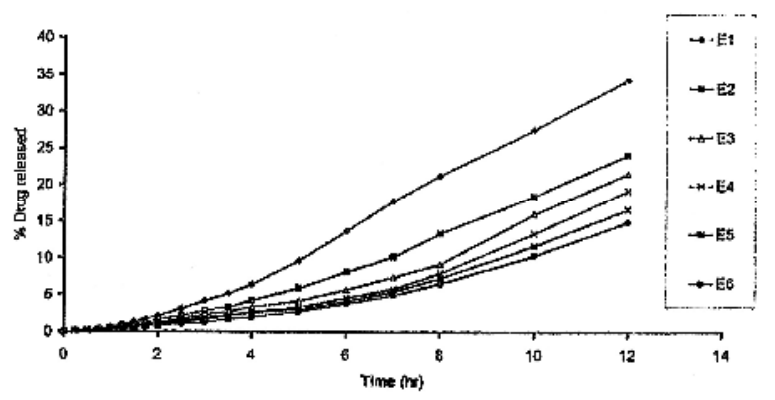

Fig. 6: In-vitro release profiles of natamycin from bioadhesive vaginal tablet formulations containing different concentrations of CP 971p.

As natamycin has very poor aqueous solubility, ${ }^{15}$ The percent drug release was $6.35 \%$ for A1 (5\% CP 974p), $4.64 \%$ for B1 (10\% CP 974p), 4.27\% for C1 (15\% CP 974p) and $4.14 \%$ for D1 (20\% CP 974p) after $12 \mathrm{hr}$. It was apparent that these percents were too small so it was decided to add PEG 6000, which was reported to increase the solubility and release rate of various poorly water-soluble drugs. $^{22,23}$ As the percent of PEG 6000 increased from 0 to $50 \%$ in formulations $\mathrm{A} 1$ to $\mathrm{A} 7$, the percent drug released was found to be increased from 6.35 to $38.83 \%$ after $12 \mathrm{hr}$ (Fig. 2). Similar results were obtained for the other tablet formulations (C-D). This increase in drug release may be attributed to the fact that as the matrix swelled, PEG 6000 was also removed by dissolution, thus creating more pores and channels for the drug to diffuse out of the tablets.

To characterize the release mechanism of natamycin, the dissolution data (Mt / $\mathrm{M} \infty$ $<0.60)$ can be fitted to the exponential release equation: ${ }^{25}$

$$
\mathrm{Mt} / \mathrm{M} \infty=\mathrm{Kt}^{\mathrm{n}}
$$


Where Mt / M $\infty$ is the fraction of drug released up to time $\mathrm{t}, \mathrm{n}$ is a diffusion exponent characterized the type of release mechanism operative during the dissolution process, $\mathrm{K}$ is a constant which incorporates the properties of the macromolecular polymeric system and the drug. The results of this fitting are presented in Table 7.

The values of $n$ are nearly 1.0 for the formulations containing low concentrations of
PEG 6000 indicating nearly zero order kinetics of drug release (case II transport). A further evidence of zero order drug release can be also seen in Figs. 2-6 where the plots showed nearly straight lines for the formulations containing low concentrations of PEG 6000. The values of $\mathrm{n}$ increased with increasing the concentration of PEG 6000 and decreasing concentration of CP 971p indicating super case II transport $(\mathrm{n}>1)$.

Table 7: Kinetic constant (k), diffusional exponent (n) and determination coefficient $\left(r^{2}\right)$ following linear regression of $\log \left(\mathrm{M}_{t} / \mathrm{M}_{\infty}\right)$ versus $\log (\mathrm{t})$ of natamycin vaginal bioadhesive tablets.

\begin{tabular}{|c|c|c|c|}
\hline Batch no. & $\mathrm{n}$ & $\mathrm{K}\left(\mathrm{hr}^{-1}\right)$ & $\mathrm{r}^{2}$ \\
\hline A1 & 1.08573 & $3.81 \times 10^{-3}$ & 0.99655 \\
\hline A2 & 1.05902 & $4.67 \times 10^{-3}$ & 0.99937 \\
\hline A3 & 1.08309 & $5.35 \times 10^{-3}$ & 0.99929 \\
\hline A4 & 1.14133 & $5.66 \times 10^{-3}$ & 0.99885 \\
\hline A5 & 1.29650 & $6.01 \times 10^{-3}$ & 0.99631 \\
\hline A6 & 1.60843 & $4.32 \times 10^{-3}$ & 0.99141 \\
\hline A7 & 1.59604 & $8.64 \times 10^{-3}$ & 0.99321 \\
\hline B1 & 1.12631 & $2.74 \times 10^{-3}$ & 0.98394 \\
\hline B2 & 0.99506 & $4.22 \times 10^{-3}$ & 0.99852 \\
\hline B3 & 0.93386 & $5.04 \times 10^{-3}$ & 0.99825 \\
\hline B4 & 1.06700 & $4.89 \times 10^{-3}$ & 0.99904 \\
\hline B5 & 1.07286 & $5.3 \times 10^{-3}$ & 0.99799 \\
\hline B6 & 1.34028 & $6.12 \times 10^{-3}$ & 0.99024 \\
\hline B7 & 1.44988 & $7.49 \times 10^{-3}$ & 0.98685 \\
\hline C1 & 0.94522 & $3.8 \times 10^{-3}$ & 0.99762 \\
\hline C2 & 1.02586 & $3.55 \times 10^{-3}$ & 0.99592 \\
\hline C3 & 1.07843 & $3.42 \times 10^{-3}$ & 0.99517 \\
\hline C4 & 1.05237 & $4.2 \times 10^{-3}$ & 0.99802 \\
\hline C5 & 1.07812 & $4.92 \times 10^{-3}$ & 0.99593 \\
\hline C6 & 1.26459 & $4.35 \times 10^{-3}$ & 0.99207 \\
\hline C7 & 1.35246 & $6.31 \times 10^{-3}$ & 0.98786 \\
\hline D1 & 0.97707 & $3.48 \times 10^{-3}$ & 0.99839 \\
\hline D2 & 0.97909 & $3.48 \times 10^{-3}$ & 0.99578 \\
\hline D3 & 0.89470 & $4.47 \times 10^{-3}$ & 0.99334 \\
\hline D4 & 1.00111 & $4.46 \times 10^{-3}$ & 0.99469 \\
\hline D5 & 1.05243 & $5.18 \times 10^{-3}$ & 0.99411 \\
\hline D6 & 1.16670 & $5.22 \times 10^{-3}$ & 0.99743 \\
\hline D7 & 1.37989 & $6.31 \times 10^{-3}$ & 0.99460 \\
\hline E1 & 1.62435 & $6.82 \times 10^{-3}$ & 0.99891 \\
\hline E2 & 1.51531 & $5.44 \times 10^{-3}$ & 0.99965 \\
\hline E3 & 1.36165 & $5.3 \times 10^{-3}$ & 0.99186 \\
\hline E4 & 1.34328 & $4.57 \times 10^{-3}$ & 0.99018 \\
\hline E5 & 1.34960 & $4.05 \times 10^{-3}$ & 0.98896 \\
\hline E6 & 1.32708 & $3.65 \times 10^{-3}$ & 0.98908 \\
\hline & & & \\
\hline
\end{tabular}


Clinical evaluation of selected natamycin bioadhesive vaginal tablets

Formulations D6 and E6 were selected for the clinical evaluation of the prepared bioadhesive tablets because these formulations gave satisfactory results in terms of percent drug released and bioadhesive strengths. In order to reduce the frequency of application to one application only, the weight of these formulations was triplicated so the weight of each investigated tablet was $600 \mathrm{mg}$ and contained $75 \mathrm{mg}$ natamycin to meet the requirements of the drug for three days. The conventional tablets (which contain $25 \mathrm{mg}$ natamycin each) contained no bioadhesive polymers so they disintegrated rapidly and required repeated application.

The results of the clinical and microbiological evaluations are shown in Tables $8-10$. The cure rates were $22.23 \%$ in patients taking the conventional natamycin tablets, $70 \%$ in patients taking formula D6 and $90 \%$ in patients taking formula E6. Statistical analysis disclosed that the percent reduction in candida count in patients taking formulations D6 and E6 was significantly higher than that in patients taking conventional NTM tablets at the confidence levels of $5 \%$ and $1 \%$, whereas there is no significant difference between D6 and E6 at the same confidence levels.

Table 8: Candida albicans colonies count before and after treatment in patients taking formula D6.

\begin{tabular}{|c|c|c|c|}
\hline $\begin{array}{c}\text { Patient } \\
\text { no. }\end{array}$ & $\begin{array}{c}\text { Count } \\
\text { before }\end{array}$ & $\begin{array}{c}\text { Count } \\
\text { after }\end{array}$ & $\begin{array}{c}\% \\
\text { Reduction }\end{array}$ \\
\hline 1 & 297 & 0 & 100 \\
\hline 2 & 47 & 0 & 100 \\
\hline 3 & 2350 & 350 & 85.1 \\
\hline 4 & 900 & 0 & 100 \\
\hline 5 & 450 & 0 & 100 \\
\hline 6 & 850 & 50 & 94.11 \\
\hline 7 & 500 & 29 & 94.2 \\
\hline 8 & 30 & 0 & 100 \\
\hline 9 & 150 & 0 & 100 \\
\hline 10 & 80 & 0 & 100 \\
\hline
\end{tabular}

Table 9: Candida albicans colonies count before and after treatment in patients taking formula E6.

\begin{tabular}{|c|c|c|c|}
\hline $\begin{array}{c}\text { Patient } \\
\text { no. }\end{array}$ & $\begin{array}{c}\text { Count } \\
\text { before }\end{array}$ & $\begin{array}{c}\text { Count } \\
\text { after }\end{array}$ & $\begin{array}{c}\% \\
\text { Reduction }\end{array}$ \\
\hline 1 & 10 & 2 & 80 \\
\hline 2 & 200 & 0 & 100 \\
\hline 3 & 135 & 0 & 100 \\
\hline 4 & 352 & 0 & 100 \\
\hline 5 & 580 & 0 & 100 \\
\hline 6 & 270 & 0 & 100 \\
\hline 7 & 300 & 0 & 100 \\
\hline 8 & 940 & 0 & 100 \\
\hline 9 & 2000 & 0 & 100 \\
\hline 10 & 300 & 0 & 100 \\
\hline
\end{tabular}

Table 10: Candida albicans colonies count before and after treatment in patients taking conventional natamycin tablets.

\begin{tabular}{|c|c|c|c||}
\hline $\begin{array}{c}\text { Patient } \\
\text { no. }\end{array}$ & $\begin{array}{c}\text { Count } \\
\text { before }\end{array}$ & $\begin{array}{c}\text { Count } \\
\text { after }\end{array}$ & $\begin{array}{c}\% \\
\text { Reduction }\end{array}$ \\
\hline 1 & 234 & 100 & 57.26 \\
\hline 2 & 540 & 270 & 50 \\
\hline 3 & 624 & 0 & 100 \\
\hline 4 & 700 & 0 & 100 \\
\hline 5 & 250 & 100 & 60 \\
\hline 6 & 300 & 120 & 60 \\
\hline 7 & 310 & 100 & 67.74 \\
\hline 8 & 150 & 56 & 62.67 \\
\hline 9 & 470 & 230 & 51.06 \\
\hline
\end{tabular}

The mean adhesion time of the bioadhesive tablets was $3.91 \pm 0.94$ days. This high adhesion time explains the higher cure rates obtained with the bioadhesive tablets because the bioadhesive polymers allow the active drug to be in contact with Candida albicans for prolonged periods of day and night times and hence increase the therapeutic efficacy of the drug and improve patient compliance due to the lower frequency of dosing. ${ }^{26}$ 


\section{Stability Studies}

The stability studies of the bioadhesive vaginal tablets revealed that no significant changes occurred in the physical parameters of the tablets. At the end of six months, the percents remaining of active drug for formula D6 were $98.1,97.8$ and 97.52 at 30,37 and $45^{\circ}$ respectively and $98.12,97.81$ and 97.49 at 30 , 37 and $45^{\circ}$ respectively for formula E6. Degradation reaction of natamycin was studied and the correlation coefficient ( $r$ ) was determined according to zero-order and firstorder reaction kinetics. The order of the reaction was found to be first order (Table 11).

The method of accelerated testing of pharmaceutical products based on the principles of chemical kinetics was demonstrated by Garrett and Carper. ${ }^{27}$ According to this technique, the $\mathrm{K}$ values for the decomposition of the drug at various elevated temperatures were obtained by plotting some function of concentration against time (Table 11). The logarithms of the specific rates of decomposition were then plotted against the reciprocals of the absolute temperatures according to the Arrhenius equation. The resulting lines were extrapolated to room temperature to obtain the $\mathrm{K}_{25}$ for each formula (Table 11). These later values were then used to calculate the shelf life of the formulations, which was found to be 2.69 years for formula D6 and 2.67 years for formula E6.

\section{Conclusion}

The present study was an attempt to develop a mucoadhesive vaginal drug delivery system for an antifungal drug (natamycin). The main advantage achieved by this dosage form resulted from its ability to prolong the local release of the drug in the vaginal cavity. The results suggest that natamycin-containing mucoadhesive vaginal tablets would be useful for effective and safe treatment of vaginal candidiasis with reduced dosing intervals and hence, improved patient compliance. The accelerated stability studies revealed that natamycin is stable in presence of the used bioadhesive polymers and tablet excipients for not less than 2.5 years.

\section{Acknowledgment}

The authors wish to thank Prof. Dr. H. M. Sabet, head of department of Obstetrics and Gynecology, and Dr. A. S. Ahmed, department of Microbiology, Faculty of Medicine, Assiut University, Assiut, Egypt for their help in performing the clinical part of this study.

Table 11: Correlation coefficients (r), rate constants (K) and $\mathrm{K}_{25}$ for formulations D6 and E6.

\begin{tabular}{|l|l|c|c|c|c|c|c|}
\hline \multicolumn{2}{|c|}{} & \multicolumn{3}{|c|}{ D6 } & \multicolumn{3}{c|}{$\mathrm{E} 6$} \\
\cline { 2 - 7 } & $30^{\circ}$ & $37.5^{\circ}$ & $45^{\circ}$ & $30^{\circ}$ & $37.5^{\circ}$ & $45^{\circ}$ \\
\hline \multirow{2}{*}{$\mathrm{r}$} & $\begin{array}{l}\text { Zero } \\
\text { order }\end{array}$ & 0.99589 & 0.99714 & 0.99618 & 0.99049 & 0.99468 & 0.99515 \\
\cline { 2 - 7 } & $\begin{array}{l}\text { First } \\
\text { order }\end{array}$ & 0.99605 & 0.99729 & 0.99636 & 0.99066 & 0.99489 & 0.99536 \\
\hline $\mathrm{K} \times 10^{5}$ & 11.55 & 13.25 & 14.72 & 11.63 & 13.47 & 14.23 \\
\hline $\mathrm{K}_{25}$ & \multicolumn{3}{|c|}{$1.07 \times 10^{-4}$} & \multicolumn{3}{c|}{$1.08 \times 10^{-4}$} \\
\hline \hline
\end{tabular}




\section{REFERENCES}

1- J. L. Lanchares and M. L. Hernandez, Int. J. Gynecol. Obstet., 71, S29-S35 (2000).

2- J. Ferrer, Int. J. Gynecol. Obstet., 71, S21S27 (2000).

3- A. A. Deshpande, C. T. Rhodes and M. Danish, Drug Dev. Ind. Pharm., 18, 12251279 (1992).

4- J. L. Richardson and L. Illum, Adv. Drug Deliv. Rev., 8, 341-366 (1992).

5- C. E. Kast, C. Valenta, M. Leopold and A. Bernkop-Schnurch, J. Control. Rel., 81, 347-354 (2002).

6- D. Duchene, F. Touchard and N. A. Peppas, Drug Dev. Ind. Pharm., 14 (2-3), 283-318 (1988).

7- A. K. Singla, M. Chawla and A. Sigh, Drug Dev. Ind. Pharm., 26 (9), 913-924 (2000).

8- J. D. Smart, I. W. Kellaway and E. C. Worthington, J. Pharm. Pharmacol., 36, 295-299 (1984).

9- T. P. Foster and E. L. Parrot, J. Pharm. Sci., 79 (9), 806-810 (1990).

10- M. R. Senguin, S. M. Liebowitz, R. E. Sarabia and J. W. Mc Ginity, J. Pharm. Sci., 79 (9), 811-816 (1990).

11- L. Brannon-Peppas, Adv. Drug Deliv. Rev., 11, 169-177 (1993).

12- G. C. Ceschel, P. Maffei, S. L. Borgia, C. Ronchi and S. Rossi, Drug Dev. Ind. Pharm., 27, 541-547 (2001).

13- J. Y. Chang, Y. Oh, H. S. Kong, E. J. Kim, D. D. Jang, K. T. Nam and C. Kim, J. Control. Rel., 82, 39-50 (2002).

14- A. Gursoy, I. Sohtorik, N. Uyanik and N. A. Peppas, S.T.P. Pharma, 5, 886-892 (1989).

15- S. C. Sweetman, Martindale: the complete drug reference. 33 rd edition. The Pharmaceutical Press, London, p. 392 (2002).
16- A. E. Rakoff, L. G. Feo, and L. Goldstein, Am. J. Obstet. Gynecol., 47, 467 (1994).

17- V. Agarwal and B. Mishra, Drug Dev. Ind. Pharm. 25, 701-709 (1999).

18- Harry Brik, Natamycin, In: "Analytical Profile of Drug Substances and Excipients", Vol., 23, H. G. Brittain (ed.), Academic Press, Inc., California, p. 517 (1994).

19- USP "The United States Pharmacopia" $24^{\text {th }}$ edn., United States Pharmacopeial Convention, Inc., Rockville, U. S. A., p. 1152 (2000).

20- R. Khanna, S. P. Agarwal and A. Ahuja, Drug Dev. Ind. Pharm., 23, 831-837, (1997).

21- C. Li, P. P. Bhatt and T. P. Johnston, Drug Dev. Ind. Pharm., 24, 919-926 (1998).

22- C. F. Wong, K. H. Yuen and K. K. Peh, Int. J. Pharm., 178, 11-22 (1999).

23- M. Pedersen and M. R. Rassing, Drug Dev. Ind. Pharm., 17, 411-420 (1991).

24- T. Save and P. Venkitachalm, Drug Dev. Ind. Pharm., 18, 1663-1679 (1992).

25- R. W. Korsmeyer, R. Gurny, E. Doelker, P. Buri and N. A. Peppas, Int. J. Pharm., 15, 25-35 (1983).

26- S. Bouckaert, M. Temmerman, J. Uoorspoels, H. Vankets, J. P. Remon and M. Dhont, J. Pharm. Pharmacol., 47, 970971 (1995).

27- E. R. Garrett and R. F. Carper, J. Am. Pharm. Assoc. Sci. Ed., 4, 515 (1955) through "Kinetics In: Physical Pharmacy, $4^{\text {th }}$ edn., Alfred Martin (ed.), Lea and Febiger, Philadelphia, p. 314 (1993). 